\title{
Co-infection of Soybean with Soybean mosaic virus and Alfalfa mosaic virus Results in Disease Synergism and Alteration in Accumulation Level of Both Viruses
}

\author{
M. Malapi-Nelson, R.-H. Wen, B. H. Ownley, and M. R. Hajimorad, Department of Entomology and Plant \\ Pathology, The University of Tennessee, Knoxville, TN 37996
}

\begin{abstract}
Malapi-Nelson, M., Wen, R.-H., Ownley, B. H., and Hajimorad, M. R. 2009. Co-infection of soybean with Soybean mosaic virus and Alfalfa mosaic virus results in disease synergism and alteration in accumulation level of both viruses. Plant Dis. 93:1259-1264.

Co-infection of potyviruses with taxonomically diverse plant viruses results in disease synergism and elevation in the level of accumulation of non-potyviruses involved. In the majority of cases, however, the accumulation level of potyviruses remains essentially unaltered. A few potyviruses, such as Soybean mosaic virus (SMV), naturally infect soybean (Glycine max). Soybean is also a natural host to a number of non-potyviruses including Alfalfa mosaic virus (AMV), which causes mild symptoms often associated with symptom remission. We have now studied the interactions between AMV and SMV on symptom severity and accumulation level of each of the two viruses in soybean. Co-infection of soybean with AMV and SMV was established following mechanical inoculation, irrespective of simultaneous or sequential introduction of the two viruses. In multiple experiments, co-infection of soybean resulted in severe symptoms in doubly infected plants in a strain-independent manner, with enhancement in the level of AMV indicating that the interaction of AMV with SMV is synergistic. Conversely, the level of SMV accumulation was reduced. This suggests that in co-infection with AMV, SMV interacts antagonistically. The observation that co-infection of AMV and SMV results in disease synergism suggests enhancement of potential that AMV may become a serious viral disease of soybean.
\end{abstract}

Soybean (Glycine $\max ($ L.) Merrill), a major legume crop in the United States, is a natural host to a number of taxonomically diverse plant viruses, including Soybean mosaic virus (SMV) and Alfalfa mosaic virus (AMV) (13). In soybean, SMV (genus Potyvirus; family Potyviridae) is considered widespread, and seven strains of the virus, identified based on differential interactions with selected soybean genotypes, have been reported from the United States (4). On the other hand, AMV (genus Alfamavirus; family Bromoviridae) is an emerging viral problem of soybean in the midwestern United States (20). In Wisconsin, AMV has been a factor in yield reduction by 31 and $26 \%$ in 2002 and 2003, respectively (20). Unlike SMV, AMV is biologically a highly variable virus (9). The recent increase in incidence of AMV in the midwestern United States is partly attributed to the introduction of the soybean-colonizing aphid (Aphis glycines) (20), which is capable of transmitting

Corresponding author: M. R. Hajimorad E-mail: mrh@utk.edu

Current address of M. Malapi-Nelson: Department of Plant Pathology, Texas A \& M University, TAMU College Station, TX 77843.

Accepted for publication 29 July 2009.

doi:10.1094/PDIS-93-12-1259

(c) 2009 The American Phytopathological Society
AMV as well as SMV among other viruses $(6,14,30)$.

In many crops, co-infection of potyviruses with taxonomically diverse plant viruses results in disease synergism and elevation in the level of the nonpotyviruses involved $(2,15,24,27)$. The elevation in the level of the nonpotyviruses has been attributed to suppression of gene silencing activity of helpercomponent proteinase (HC-Pro) of potyviruses $(17,23)$. In the majority of these interactions, however, the accumulation level of the potyvirus remained essentially unchanged (16). Nevertheless, there are instances where potyviruses interact antagonistically in co-infection $(21,22)$.

In soybean, synergistic interaction of Bean pod mottle virus (BPMV) and Cowpea mosaic virus (CPMV), both belonging to the genus Comovirus, family Comoviridae, with SMV has been reported $(2,3,15,24)$. Recently, however, this was attributed to the ability of HC-Pro cistron of SMV in suppressing virus-induced gene silencing (32). In these instances, however, the level of SMV in doubly infected plants remained essentially unaltered as compared to single infection $(2,3)$. Nevertheless, in one instance, reduction in the level of SMV in the presence of BPMV was observed (3).

This study was conducted to investigate the impact of AMV and SMV co-infection in soybean on disease phenotype and accumulation level of the two viruses. Such a study was needed because AMV is an emerging viral problem of soybean in the midwestern United States, and SMV, a seedborne virus, is widespread in many soybean growing areas. Furthermore, the soybean aphid that is present in many soybean growing areas of the northern states serves as an efficient vector of both AMV and SMV $(6,14,30)$. Hence, the objectives of this study were to (i) determine if coinfection of soybean with AMV and SMV can be established, and whether coinfection results in synergism; (ii) determine if synergism induced by co-infection of soybean with AMV and SMV is virus strain-independent; and (iii) determine the level of accumulation of each of the viruses in co-infection in comparison to single infection.

\section{MATERIALS AND METHODS}

Viruses. AMV strains used in this study, Joe Davis (JD) and Champaign (Ch), were originally isolated from naturally infected soybeans in Illinois and kindly provided by L. L. Domier (University of Illinois at Urbana-Champaign). A biologically purified isolate of each virus was obtained following serial local lesion transfers for at least three times on Phaseolus vulgaris (cv. Rome) and Vigna unguiculata (cv. Blackeye), respectively. The stocks of the resultant biologically purified viruses were maintained in soybean cv. Colfax that was kindly provided by C. R. Grau (University of Wisconsin). SMV sources were progeny viruses derived from molecularly cloned strains G7 (8) and N (an isolate of strain G2) (29) in soybean cv. Williams82. Virus indexed Williams 82 seeds used were produced in our laboratory.

Propagation and purification of viruses. Soybean cv. Williams 82 was used as a host for propagation of all the viruses. AMV was essentially purified according to Hajimorad and Francki (9) and SMV according to Hajimorad and Hill (11). Virion concentrations were determined spectrophotometrically. Purified AMV virions in $0.01 \mathrm{M}$ phosphate buffer, $\mathrm{pH} 7.0$, and $50 \%$ glycerol were stored at $-20^{\circ} \mathrm{C}$. SMV virions in $0.05 \mathrm{M} \mathrm{Na-borate,} \mathrm{pH} 8.0$, were kept at $4{ }^{\circ} \mathrm{C}$ or at $-80^{\circ} \mathrm{C}$.

Virus inoculation. Soybean plants were inoculated with sap from infected plants or purified virions. Sap inoculum was prepared by grinding young soybean leaves infected with either AMV or SMV in 0.01 or $0.1 \mathrm{M}$ phosphate buffer, $\mathrm{pH} 7.1$, respec- 
tively $(9,11)$, in a ratio of $1: 10(\mathrm{wt} / \mathrm{vol})$ by using chilled mortars and pestles. For the co-inoculation experiments, sap containing AMV or SMV virions was mixed (1:1 $\mathrm{vol} / \mathrm{vol}$ ) and a mixture of $10 \mu \mathrm{l}$ was rub- inoculated by using a forefinger to each of the Carborundum-dusted (600 mesh) unifoliate leaves. For single virus inoculation, sap containing either AMV or SMV virions was mixed with similarly prepared sap

\section{Inoculum}

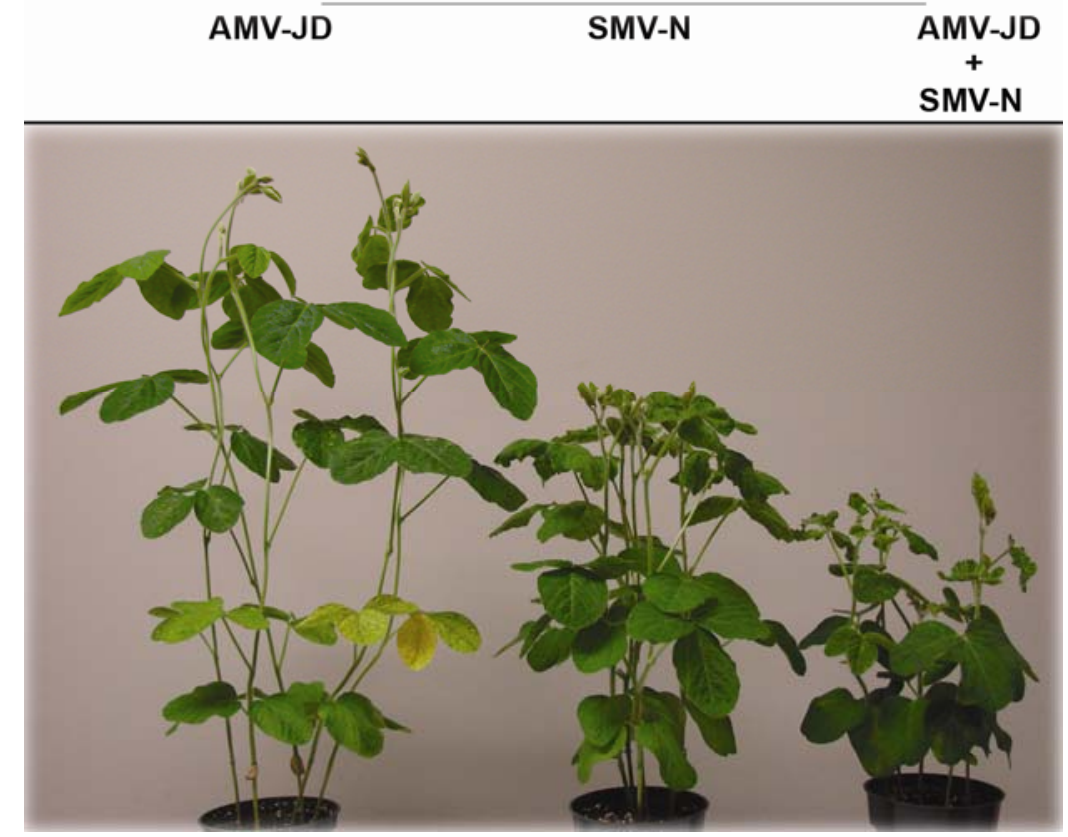

Fig. 1. Phenotypic response of soybean cv. Williams 82 to mechanical inoculation with purified virions of Alfalfa mosaic virus (AMV)-JD or Soybean mosaic virus (SMV)-N individually or in combination (AMV-JD + SMV-N). Unifoliate leaf of each plant was mechanically inoculated with $1.5 \mu \mathrm{g}$ of virion in $10 \mu \mathrm{l}(3 \mu \mathrm{g} / \mathrm{plant})$ for single inoculation or a mixture of $3 \mu \mathrm{g}$ virion of AMV-JD and SMV-N with a ratio of $1: 1(\mathrm{wt} / \mathrm{wt})$ in $10 \mu \mathrm{l}$ (a total of $6 \mu \mathrm{g} / \mathrm{plant}$ ) for double inoculation. Inoculated plants were kept in a growth chamber $\left(25^{\circ} \mathrm{C}\right)$ with a photoperiod of $16 \mathrm{~h}$ until photographed 21 days postinoculation.

Table 1. Analysis of accumulation of Alfalfa mosaic virus (AMV)-JD and Soybean mosaic virus (SMV)-N by indirect enzyme-linked immunosorbent assay (ELISA) in soybean cv. Williams82 following single or double inoculation

\begin{tabular}{|c|c|c|c|c|}
\hline $\begin{array}{l}\text { Treatments } \\
\text { comparison }\end{array}$ & $\begin{array}{c}\text { Primary } \\
\text { inoculation }^{w}\end{array}$ & $\begin{array}{c}\text { Secondary } \\
\text { inoculation }^{x}\end{array}$ & $\begin{array}{c}\text { Absorbance } \\
\text { value }^{\mathrm{y}}\end{array}$ & $\begin{array}{c}\text { Ratio } \\
\text { dual/single }\end{array}$ \\
\hline \multicolumn{5}{|l|}{ AMV } \\
\hline & AMV-JD & Mock & $0.11 \pm 0.02 b$ & \\
\hline & SMV-N+AMV-JD & $-^{\mathrm{z}}$ & $0.31 \pm 0.02 \mathrm{a}$ & 2.8 \\
\hline & AMV-JD & Mock & $0.11 \pm 0.02 b$ & \\
\hline & SMV-N & AMV-JD & $0.39 \pm 0.02 \mathrm{a}$ & 3.5 \\
\hline & AMV-JD & Mock & $0.11 \pm 0.02 b$ & \\
\hline & AMV-JD & SMV-N & $0.37 \pm 0.02 \mathrm{a}$ & 3.4 \\
\hline \multicolumn{5}{|l|}{ SMV } \\
\hline & SMV-N & Mock & $0.55 \pm 0.14 \mathrm{a}$ & \\
\hline & SMV-N+AMV-JD & - & $0.40 \pm 0.14 b$ & 0.7 \\
\hline & SMV-N & Mock & $0.55 \pm 0.14 \mathrm{a}$ & \\
\hline & SMV-JD & AMV-JD & $0.40 \pm 0.14 b$ & 0.7 \\
\hline & SMV-N & Mock & $0.55 \pm 0.14 \mathrm{a}$ & \\
\hline & AMV-JD & SMV-N & $0.45 \pm 0.14 \mathrm{a}$ & 0.8 \\
\hline
\end{tabular}

${ }^{\mathrm{w}}$ Unifoliate leaves were inoculated with sap containing virions of AMV-JD or SMV-N for single inoculation, or a mixture of sap for co-inoculation.

${ }^{x}$ Second inoculations were done $4 \mathrm{~h}$ post primary inoculations with infectious sap from infected plants or from noninoculated leaves (mock).

y Absorbance values at $405 \mathrm{~nm}$ for a dilution of 1:10 (wt/vol) sap extract in carbonate buffer, $\mathrm{pH}$ 9.6. Middle leaflet from each trifoliate leaf was harvested, leaflets from the same plant combined, sap extracted and subjected to ELISA. Values are least square means \pm SE from a total of six replicate plants; data from two independent experiments where leaf samples were harvested in one experiment at 21 days postinoculation (dpi) and the other at 30 dpi were pooled for analysis. For each pair of treatments, mean values followed by the same letter are not significantly different according to an $F$ protected LSD at $P=0.05$.

${ }^{\mathrm{z}}$ No secondary inoculation was done. obtained from virus-free soybean plants with a ratio of $1: 1$, and a mixture of $10 \mu \mathrm{l}$ was applied to each of the unifoliate leaves. When purified virions served as inoculum, except as otherwise stated, each unifoliate leaf was inoculated with $5 \mu \mathrm{g}$ of purified virions in a total volume of $10 \mu \mathrm{l}$ for single inoculation or a mixture of $10 \mu \mathrm{g}$ in a total volume of $10 \mu \mathrm{l}(5 \mu \mathrm{g}$ each of the viruses) for co-inoculation experiments. In sequential inoculation, unifoliate leaves that were initially inoculated with one of the viruses were reinoculated with the other virus $4 \mathrm{~h}$ post primary inoculation. The inoculated plants were maintained in a growth chamber operating at $25^{\circ} \mathrm{C}$ with a photoperiod of $16 \mathrm{~h}$ until evaluated for the presence of symptoms or accumulation of viruses at 21 or 30 days postinoculation (dpi). Each experiment was repeated at least twice with a minimum of three replicate plants for each treatment.

Evaluation of AMV and SMV coat protein $(\mathrm{CP})$ accumulation by indirect enzyme-linked immunosorbent assay (ELISA). Antigen coated indirect ELISA as described by Hajimorad and Francki (10) was used to monitor the accumulation level of SMV and AMV in infected soybean tissues, except that a solution of $5 \%$ nonfat milk in phosphate buffer saline (PBS), pH 7.4, served as a blocking solution and for dilution of antibodies. Sap was extracted in the presence of carbonate buffer, pH 9.6 (1.59 $\mathrm{g}$ of $\mathrm{Na}_{2} \mathrm{CO}_{3}$ and 2.93 $\mathrm{g}$ of $\mathrm{NaHCO}_{3}$ per liter of distilled water) (5) with a ratio of $1: 10(\mathrm{wt} / \mathrm{vol})$, clarified and added to the Immulon $1 \mathrm{~B}$ microtiter wells (Thermo Scientific "Nunc", Milford, MA). Except as otherwise stated, sap was extracted from the middle leaflet of each of the trifoliate leaves of inoculated plants. Polyclonal antibodies against AMV (9) and SMV (University of TennesseeVirology Collection) diluted 1:1,000 ( $\mathrm{vol} / \mathrm{vol})$ were used for detection of viruses, and affinity purified alkaline phosphatase-conjugated goat anti-rabbit IgG (Sigma-Aldrich, St. Louis, MO) at a dilution of $0.6 \mu \mathrm{l} / \mathrm{ml}$ was used as the probing antibody. The main effect of co-infection of soybeans with AMV and SMV on accumulation of viruses, based on ELISA readings at $405 \mathrm{~nm}$ with a Microplate Reader Model 680 from Bio-Rad (Hercules, CA), was analyzed for significance using Proc Mixed of PC-SAS ver. 9.1.3 (SAS Institute, Cary, NC). Significant effects were further analyzed with an $F$ protected least significant difference (LSD) test at $P=0.05$.

Semiquantitative reverse transcription-polymerase chain reaction (RTPCR). For each treatment, including mock, one leaf disk $(\sim 1 \mathrm{~cm}$ diameter $)$ was harvested from each leaflet of trifoliate leaves one to five from five independent replicate plants at 21 or $28 \mathrm{dpi}$. To collect the disks, the leaf lamina was placed between the lid and the tube opening of a 
microfuge tube, and by closing the lid, disks were punched directly into the tube. The leaf disks for each treatment, a total of 25, were combined, and total RNA was extracted with the RNeasy Plant Mini Kit (Qiagen, Valencia, CA) according to the manufacturer's instructions. Total RNA was quantified by using a SmartSpec Plus Spectrophotometer (Bio-Rad), and $2.5 \mu \mathrm{g}$ from each treatment was reverse transcribed by using SuperScript III Reverse Transcriptase (Invitrogen, Carlsbad, CA) according to the manufacturer's instructions using specific primers to soybean ubiquitin gene (Ubi-r: 5'-CACGAAGAC GCAACACCAAG-3') (GenBank Accession no. D28123); AMV (AMV-r: 5'TTCATACCTTGACCTTAATCCACCC$3^{\prime}$ ) (Accession no. NC_002025); and SMV-r1 (5'-AAACCTGTTGATTTCCCT GAGCC-3') (Accession no. D00507). As controls, $2.5 \mu \mathrm{g}$ total RNA for each treatment was also reverse transcribed under the same conditions, except no RT was added. Semi-quantitative RT-PCR was optimized according to Marone et al. (19), and ubiquitin gene was used as an internal control. The cDNAs of AMV and SMV were diluted 1:1,000 and that of ubiquitin at $1: 100$, and $1 \mu \mathrm{l}$ of each served as a template in PCR in the presence of 1 unit $(0.2$ $\mu \mathrm{l})$ of Ex Taq (Takara Bio, Madison, WI). Specific primers Ubi-r and Ubi-f (5'CCATAACCCTAGAGGTTGAAAGC- $3^{\prime}$ ) were used for ubiquitin; AMV-r and AMV-f (5'-TTCTCAGAACTATGCTGCTTTACG C- $\left.3^{\prime}\right)$ for AMV; and SMV-r2 (5'-CCA AATTTGCAATTTTGGCTGCTG-3') and SMV-f (5'-ATTTTGGTTGACCATGCGT$3^{\prime}$ ) for SMV amplifications. PCR reactions were carried out in a PTC-200 DNA Engine Thermal Cycler (Bio-Rad). The PCR program for ubiquitin amplification consisted of a cycle of $4 \mathrm{~min}$ at $95^{\circ} \mathrm{C} ; 30 \mathrm{~s}$ at $95^{\circ} \mathrm{C}, 30 \mathrm{~s}$ at 69 and $30 \mathrm{~s}$ at $72^{\circ} \mathrm{C}, 22$ cycles; followed by $10 \mathrm{~min}$ at $72^{\circ} \mathrm{C}$. Similar conditions were adopted for amplification of AMV and SMV; except annealing was done at $67^{\circ} \mathrm{C}$ with a total of 18 cycles. The PCR products were evaluated following electrophoresis in ethidium bromide-stained agarose gels, and images were acquired with a ChemiDoc XRS (Bio-Rad).

\section{RESULTS AND DISCUSSION}

To find out if co-infection of AMV and SMV in soybean plants requires simultaneous or sequential introduction of the viruses, we initially experimented with AMV-JD and SMV-N. Inoculation of soybean cv. Williams82 with AMV-JD alone resulted in moderate mosaic followed by strong chlorosis of the lower trifoliate leaves, in particular the first trifoliate leaf; however, the upper trifoliate leaves were almost symptomless by 21 to 28 dpi (Fig. 1 ). The presence of symptoms induced by AMV-JD in trifoliate leaves at different positions correlated directly with the level of virus accumulated in these leaves (18).
Similar observations have been reported with AMV infection in tobacco, where symptom remission also occurs (16). In contrast to AMV infection, Williams82 soybean plants singly infected with SMV$\mathrm{N}$ exhibited moderate stunting, severe mosaic, and distortion of the upper trifoliate leaves (Fig. 1). Furthermore, the accumulation level of SMV-N CP remained relatively high in all the systemically infected trifoliate leaves examined (18).

Irrespective of simultaneous or sequential application of SMV-N and AMV-JD to soybean cv. Williams82, co-infection with both viruses was established (Table 1) and the infected plants showed strong stunting together with severe mottling and leaf deformation (Fig. 1). Co-infected plants did not exhibit any sign of symptom remission when evaluated 21 or 30 dpi. Symptom severity was associated with significant enhancement in accumulation level of AMV-JD in systemically infected trifoliate leaves $(P<0.0001)$ as compared to single infection (Table 1). Similar observations were made when soybean plants were inoculated sequentially instead of simultaneously (Table 1). Furthermore, the results remained the same when the infected plants were evaluated 21 or $30 \mathrm{dpi}$. These results are all in agreement with synergistic interaction of BPMV with SMV in soybean (2). However, the level of accumulation of SMV-N decreased significantly in co-infection with AMV-JD, but only when the viruses were introduced simultaneously (Table 1) or sequential inoculation was done initially with SMV-N followed by inoculation with AMV-JD (Table 1). Although the accumulation level of SMV-N also decreased when the plants were inoculated initially with AMV-JD followed after $4 \mathrm{~h}$ by SMV-N inoculation, the level of reduction was not significant (Table 1). These observations are in contrast with the other potyvirus-associated synergistic diseases where no alteration in the level of potyviruses involved was reported $(2,27)$. As simultaneous inoculation of soybean plants with AMV and SMV

Table 2. Analysis of accumulation of Alfalfa mosaic virus (AMV)-Ch and Soybean mosaic virus (SMV)-N by indirect enzyme-linked immunosorbent assay (ELISA) in soybean cv. Williams82 following single or double inoculation

\begin{tabular}{lccc}
\hline Treatment comparison & Inoculum $^{\mathbf{y}}$ & Absorbance value $^{\mathbf{z}}$ & Ratio dual/single \\
\hline AMV & AMV-Ch & $0.38 \pm 0.14 \mathrm{~b}$ & \\
& AMV-Ch + SMV-N & $0.6 \pm 0.14 \mathrm{a}$ & 1.6 \\
SMV & SMV-N & $0.85 \pm 0.05 \mathrm{a}$ & \\
& AMV-Ch + SMV-N & $0.67 \pm 0.05 \mathrm{~b}$ & 0.8 \\
\hline
\end{tabular}

${ }^{\mathrm{y}}$ Unifoliate leaves were inoculated with purified virions of AMV-Ch or SMV-N for single inoculation, or a mixture of the two viruses for co-inoculation.

${ }^{z}$ Absorbance values at $405 \mathrm{~nm}$ for a dilution of 1:10 (wt/vol) sap extract in carbonate buffer, $\mathrm{pH}$ 9.6. Middle leaflet from each trifoliate leaf was harvested, leaflets from the same plant combined, sap extracted and subjected to ELISA. Values are least square means \pm SE from a total of 10 replicate plants; data from two independent experiments where leaf samples were harvested in one at 21 days postinoculation (dpi) and the other at 30 dpi were pooled for analysis. For each pair of treatments, mean values followed by the same letter are not significantly different according to an $F$ protected LSD at $P=0.05$.

Table 3. Analyses of accumulation of Alfalfa mosaic virus (AMV) isolates JD and Ch and Soybean mosaic virus (SMV)-G7 by indirect enzyme-linked immunosorbent assay (ELISA) in soybean cv. Williams82 following single or double inoculation

\begin{tabular}{lcccc}
\hline $\begin{array}{l}\text { Treatment } \\
\text { comparison }\end{array}$ & Inoculum & $\begin{array}{c}\text { Replicate } \\
\text { plants }\end{array}$ & $\begin{array}{c}\text { Absorbance } \\
\text { value }^{\mathbf{z}}\end{array}$ & $\begin{array}{c}\text { Ratio } \\
\text { dual/single }^{\mathbf{y}}\end{array}$ \\
\hline AMV & AMV-JD & 9 & $1.5 \pm 0.14 \mathrm{~b}$ & \\
& AMV-JD + SMV-G7 & 15 & $1.9 \pm 0.11 \mathrm{a}$ & 1.3 \\
& AMV-Ch & 8 & $1.16 \pm 0.14 \mathrm{~b}$ & \\
& AMV-Ch + SMV-G7 & 14 & $1.7 \pm 0.1 \mathrm{a}$ & 1.5 \\
SMV & SMV-G7 & 9 & $0.89 \pm 0.07 \mathrm{a}$ & \\
& AMV-JD + SMV-G7 & 15 & $0.7 \pm 0.07 \mathrm{a}$ & 0.8 \\
& SMV-G7 & 8 & $0.89 \pm 0.07 \mathrm{a}$ & \\
& AMV-Ch + SMV-G7 & 14 & $0.54 \pm 0.1 \mathrm{~b}$ & 0.6 \\
\hline
\end{tabular}

${ }^{y}$ Unifoliate leaves were inoculated with purified virions of either AMV isolates JD or Ch, or SMV-G7 for single inoculation, or a mixture of AMV and SMV for co-inoculation.

${ }^{\mathrm{z}}$ Absorbance values at $405 \mathrm{~nm}$ for dilution 1:10 (wt/vol) of sap extracts in carbonate buffer, $\mathrm{pH}$ 9.6. A leaf disk ( $1 \mathrm{~cm}$ diameter) was harvested at 21 days postinoculation from each leaflet of every trifoliate leaf of the inoculated plants. Disks from the same plant were combined, and sap was extracted and subjected to ELISA. Values are least square means \pm SE for each treatment. For each pair of treatments, mean values followed by the same letter are not significantly different according to an $F$ protected LSD at $P=0.05$ 
was shown to establish co-infection, this format of inoculation was utilized in all experiments that followed.

To determine if synergistic interaction between AMV-JD and SMV-N and antagonistic interaction between SMV-N and AMV-JD is not AMV strain-specific, AMV-Ch instead of AMV-JD was utilized. In singly infected plants, AMV-Ch induced mild mosaic and chlorosis of lower trifoliate leaves of Williams82 soybean plants as well as symptom remission in the upper trifoliate leaves 21 to 28 dpi. Co-infection of Williams82 plants with SMV-N and AMV-Ch also induced disease synergism, where the infected plants exhibited severe symptoms. In general, dual-infected plants had more pronounced stunting, chlorosis, and mosaic as well as leaf deformation when compared to singly infected plants with either AMV-Ch or SMV-N. The severity of symptoms was more pronounced in the second and the third trifoliate leaves. Again, the level of accumulation of AMVCh was significantly higher in co-infection as compared to single infection (Table 2). On the other hand, the level of SMV-N was significantly reduced when compared with the accumulation level of the virus in singly infected plants (Table 2). These observations suggest that in soybean, AMV interacts synergistically with SMV-N in a strain-non-specific manner.

It has been suggested that the extent of the synergistic interaction between SMV and BPMV is SMV strain-dependent (24).
To find out if synergism between AMV and SMV is SMV strain-dependent, SMVG7 instead of SMV-N was used. SMV-G7, in contrast to SMV-N, induces very mild mosaic and mild leaf distortion with very little or no stunting in Williams82 soybean plants (8). Nevertheless, co-infection of plants with SMV-G7 and AMV-JD or AMV-Ch also resulted in disease synergism and enhancement in the level of AMV CP (Table 3). The resultant symptoms were less severe compared to coinfection involving SMV-N and the same AMV strains. However, co-infection of soybean with SMV-G7 with either of the AMV strains resulted in reduction in accumulation of SMV-G7 (Table 3), but the level of decrease was significant in the
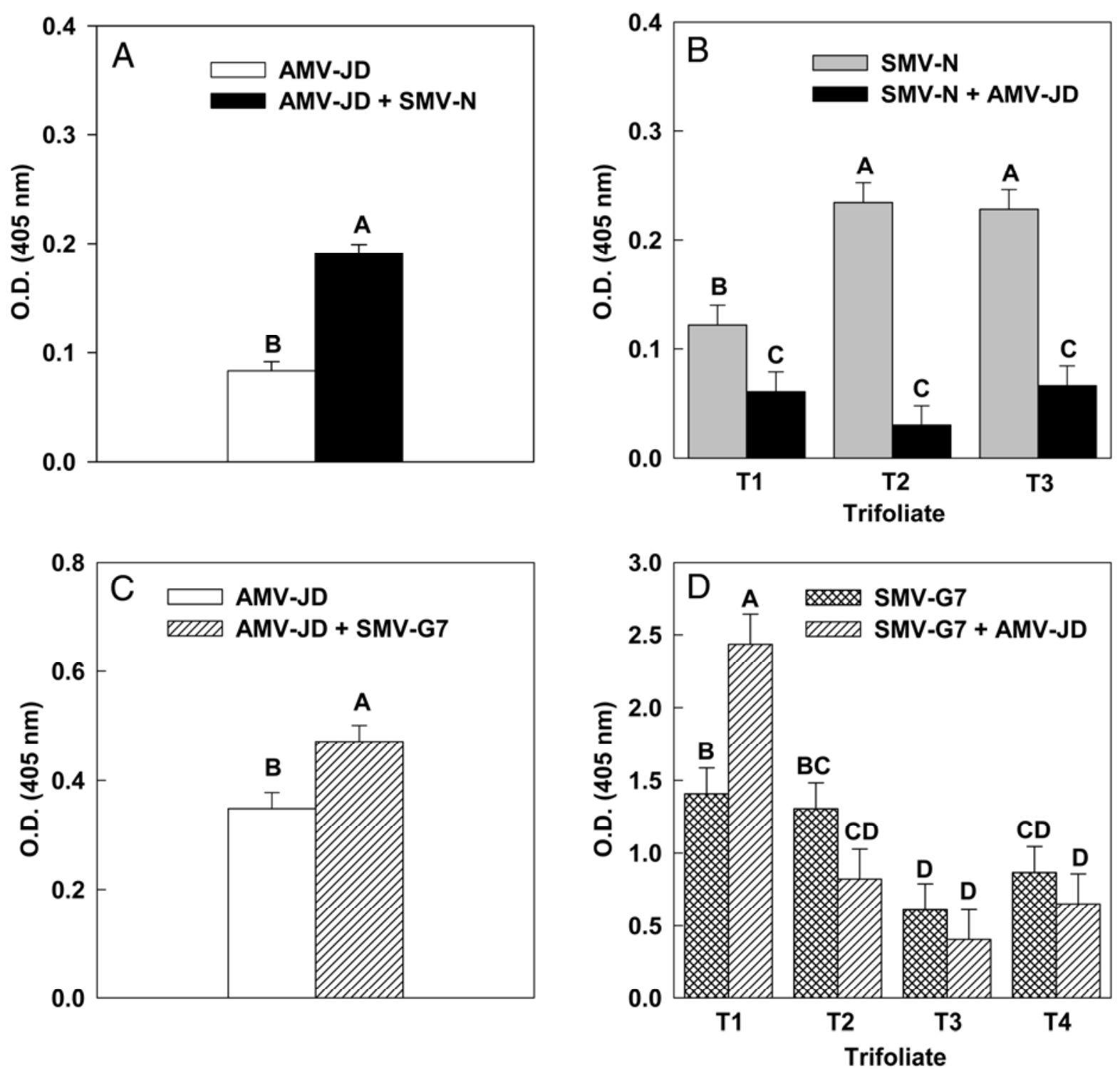

Fig. 2. Indirect enzyme-linked immunosorbent assay (ELISA) analysis of accumulation of Alfalfa mosaic virus (AMV) and Soybean mosaic virus (SMV) in systemically infected trifoliate leaves (T1 to T4) of soybean cv. Williams82 following single or double inoculation. AMV isolate or SMV strains were mechanically inoculated, individually or in combination, to unifoliate leaves of plants. Inoculated plants were maintained in a growth chamber at $25^{\circ} \mathrm{C}$ until a middle leaflet from each of the trifoliate leaves was collected 21 days postinoculation; sap was extracted and subjected to ELISA using polyclonal antibodies against coat protein of AMV (A, C) or SMV (B, D). The main effect of co-infection on accumulation of AMV-JD is shown across all trifoliates (T1 to T3) in the presence of SMV-N and (T1 to T4) in the presence of SMV-G7 (A, C); however, for SMV, accumulation is shown in individual trifoliate (B, D). Bars are least square means \pm SE from at least three replicate plants. For each pair of treatment means, bars with the same letter are not significantly different according to an $F$ protected LSD at $P=0.05$. 
case of interaction with AMV-Ch only (Table 3). These observations suggest that synergistic interaction of AMV with SMV is SMV strain-independent. of AMV and reduction in the level of SMV occurs in all trifoliate leaves, we assessed the accumulation level of each of the viruses in every trifoliate leaf in comparison with those of plants infected singly (Fig. 2). For accumulation of AMV-JD in the presence of SMV-N, the main effects of virus treatment and trifoliate position were both significant $(P<0.0001)$, but the interaction was not. SMV-N significantly enhanced the level of AMV-JD in all three trifoliate leaves as compared to those of singly infected plants at $21 \mathrm{dpi}$ (Fig. 2A). Similar to results with SMV-N, the main effects of virus treatment $(P=0.0048)$ and trifoliate $(P<0.0001)$ were significant, while the interaction of these factors was not for accumulation of AMV-JD in the presence of SMV-G7. Across all trifoliates, the level of AMV-JD was higher in the presence of SMV-N and SMV-G7 when compared to corresponding leaves of singly infected plants (Fig. 2A and C). The interaction of virus treatment and trifoliate was significant for accumulation of both SMV-N $(P=0.0014$; Fig. $2 \mathrm{~B})$ and SMVG7 $(P=0.0013$; Fig. 2D). Although the difference was not always significant at each trifoliate, in general, the level of accumulation of SMV-N and SMV-G7 decreased in the presence of AMV-JD in all the trifoliate leaves examined, except for SMV-G7 in the first trifoliate leaf (Figs. $2 \mathrm{~B}$ and $\mathrm{D})$.

We also evaluated the effect of coinfection of soybean with AMV and SMV on the level of viral RNA accumulation at 21 dpi by semiquantitative RT-PCR. The level of accumulation of AMV-JD RNA
To find out if enhancement in the level

was enhanced in the presence of both SMV-N and SMV-G7 (Fig. 3). Interestingly, similar to the observations made by indirect ELISA, the level of RNA of both SMV-N and SMV-G7 was also reduced in co-infection with AMV-JD. Analyses of tissues from the same plants collected 28 dpi also showed similar results (data not shown). Thus, an increase in the level of $\mathrm{CP}$ accumulation of AMV and a decrease in that of SMV CP observed in indirect ELISA parallel that of RNA accumulation.

In potyvirus-associated synergistic interaction with Potato virus $X$, it has been shown that the relationship between viral titer enhancement and synergism is host dependent (7). Thus, we investigated whether the pattern of interactions of AMV and SMV during co-infection in soybean is soybean cultivar-specific. However, replacement of $\mathrm{cv}$. Williams82 with $\mathrm{cv}$. Lee68 did not change the pattern of accumulations of these viruses from those observed in Williams82 (18).

The underlying mechanisms of synergistic interaction of AMV with SMV and antagonistic interaction of SMV with AMV in soybean remain to be understood. Suppression of gene silencing activity of HC-Pro has been implicated as the underlying mechanism of synergism mediated by potyviruses $(1,23,25,32)$. It is likely that a similar mechanism operates in the case of synergistic interaction between AMV and SMV. No suppression of gene silencing activity has been reported in the case of AMV (28), and this may account for symptom remission associated with AMV infection. Comparison of the level of accumulation of small interfering RNAs (SiRNA) (12) in plants infected with AMV alone with those of plants co-infected with SMV can reveal this possibility. In the majority of potyvirus-associated synergis-

\section{Inoculum}

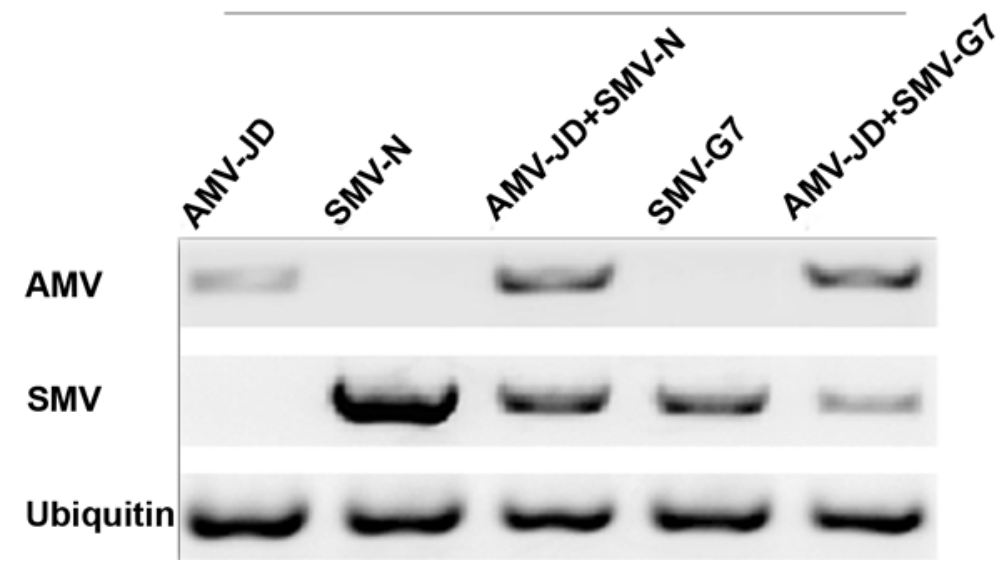

Fig. 3. Semiquantitative reverse transcription-polymerase chain reaction (RT-PCR) analysis of Alfalfa mosaic virus (AMV)-JD, Soybean mosaic virus (SMV)-N or SMV-G7 accumulations in systemically infected trifoliate leaves of soybean cv. Williams82. Each of the viruses was mechanically inoculated, individually or in combination, to unifoliate leaves of five plants. Inoculated plants were maintained in a growth chamber at $25^{\circ} \mathrm{C}$ until a disk $(\sim 1 \mathrm{~cm}$ diameter) was harvested 21 days postinoculation from each of the trifoliolate leaves. Disks derived from plants inoculated with the same inoculum were combined; total RNA was extracted and subjected to semiquantitative RT-PCR analyses for AMV, SMV, or soybean ubiquitin transcript (Ubiquitin) that was utilized for normalization. tic diseases, no reduction in the level of potyviruses involved has been reported $(2,27)$. In the current study, one cannot exclude the possibility that the soybean gene silencing machinery activated in response to co-infection with AMV and SMV is not targeting SMV genome for degradation. Assessment of the level of SiRNAs of SMV generated in single infection as compared to those accumulated during co-infection with AMV may reveal such a possibility. However, it is equally possible that SMV and AMV compete for a similar site(s) or host factor(s) during replication; hence, reduction in the level of SMV is possibly a consequence of such a competition.

We did not study the impact of coinfection of soybean with AMV and SMV on yield, seed quality, and transmission efficiency of AMV. In general, irrespective of the strains of viruses utilized in this study, the severity of symptoms was consistently higher in co-infection of soybean with AMV and SMV. Thus, it is likely that co-infection will have a negative impact on soybean yield. The role of SMV infection in causing seed coat mottling of soybean has been well established (26). It remains to be seen if co-infection with SMV and AMV has any impact on soybean seed mottling. An increase in the level of soybean seed mottling has been reported in co-infection with SMV and BPMV (24). In co-infection, an increase in efficiency of vector transmission of viruses as a result of enhancement in accumulation has been reported (31). This phenomenon has epidemiological impact. Thus, future studies will concentrate on assessing the impact of AMV and SMV co-infection on soybean yield and seed quality, as well as the efficiency of AMV transmission by aphids.

\section{ACKNOWLEDGMENTS}

The authors are grateful to L. L. Domier (University of Illinois at Urbana-Champaign) for providing the AMV isolates, C. R. Grau (University of Wisconsin) and M. A. Saghai Maroof (Virginia Tech) for providing seeds of soybean cvs. Colfax and Lee68, respectively, and M. Mazarei (The University of Tennessee) for critical reading of the manuscript. This work was supported in part by North Central Soybean Research Board and Tennessee Agricultural Experiment Station, The University of Tennessee, Knoxville.

\section{LITERATURE CITED}

1. Anandalakshmi, R., Pruss, G. J., Ge, X Marathe, R., Mallory, A. C., Smith, T. H., and Vance, V. B. 1998. A viral suppressor of gene silencing in plants. Proc. Natl. Acad. Sci. USA 95:13079-13084.

2. Anjos, J. R., Jarlfors, U., and Ghabrial, S. A. 1992. Soybean mosaic potyvirus enhances the titer of two comoviruses in dually infected soybean plants. Phytopathology 82:1022-1027.

3. Calvert, L. A., and Ghabrial, S. A. 1983. Enhancement by soybean mosaic virus of bean pod mottle virus titer in doubly infected soybean. Phytopathology 73:992-997.

4. Cho, E.-K., and Goodman, R. M. 1979. Strains of soybean mosaic virus: Classification based on virulence in resistant soybean cultivars. Phytopathology 69:467-470. 
5. Clark, M. F., and Adams, A. N. 1977. Characteristics of the microplate method of enzymelinked immunosorbent assay for the detection of plant viruses. J. Gen. Virol. 34:475-483.

6. Clark, A. J., and Perry, K. L. 2002. Transmissibility of field isolates of soybean viruses by Aphis glycines. Plant Dis. 86:1219-1222.

7. Gonsalez-Jara, P., Tenllado, F., MartinezGarcia, B., Atencio, F. A., Barajas, D., Vargas, M., Diaz-Ruiz, J., and Diaz-Ruiz, J. R. 2004. Host-dependent differences during synergistic infection by Potyviruses with potato virus X. Mol. Plant Pathol. 5:29-35.

8. Hajimorad, M. R., Eggenberger, A. L., and Hill, J. H. 2003. Evolution of Soybean mosaic virus-G7 molecularly cloned genome in Rsv1genotype soybean results in emergence of a mutant capable of evading Rsv1-mediated recognition. Virology 314:497-509.

9. Hajimorad, M. R., and Francki, R. I. B. 1988. Alfalfa mosaic virus isolates from lucerne in South Australia: Biological variability and antigenic similarity. Ann. Appl. Biol. 113:45-54.

10. Hajimorad, M. R., and Francki, R. I. B. 1991. Some observations on the binding properties of alfalfa mosaic virus to polystyrene and its significance to indirect ELISA. Arch. Virol. 117:219-235.

11. Hajimorad, M. R., and Hill, J. H. 2001. Rsv1mediated resistance against Soybean mosaic virus $-\mathrm{N}$ is hypersensitive response-independent at inoculation site, but has the potential to initiate a hypersensitive response-like mechanism. Mol. Plant-Microbe Interact. 14:587598.

12. Hamilton, A., and Baulcombe, D. C. 1999. A species of small antisense RNA in posttranscriptional gene silencing in plants. Science 286:950-952.

13. Hartman, G. L., Sinclair, J. B., and Rupe, J. C., eds. 1999. Compendium of Soybean Diseases. 4th ed. American Phytopathological Society, St. Paul, MN.

14. Hill, J. H., Alleman, R., Hogg, D. B., and Grau, C. R. 2001. First report of transmission of Soybean mosaic virus and Alfalfa mosaic virus by Aphis glycines in the New World. Plant Dis. 85:561.

15. Hobbs, H. A., Hartman, G. L., Wang, Y., Hill, C. B., Bernard, R. L., Pederson, W. L., and Domier, L. L. 2003. Occurrence of seed coat mottling in soybean plants inoculated with Bean pod mottle virus and Soybean mosaic virus. Plant Dis. 87:1333-1336.

16. Hull, R. 2002. Matthew's Plant Virology. Academic Press, New York

17. Latham, J. R, and Wilson, A. K. 2008. Transcomplementation and synergism in plants: Implications for viral transgenes? Mol. Plant Pathol. 9:85-103.

18. Malapi-Nelson, M. 2008. Interactions between Alfalfa mosaic virus and Soybean mosaic virus in soybean. M.Sc. thesis. Department of Entomology and Plant Pathology, The University of Tennessee, Knoxville.

19. Marone, M., Mozzetti, S., De Ritis, D., Pierelli, L., and Scambia, G. 2001. Semiquantitative RT-PCR analysis to assess the expression levels of multiple transcripts from the same sample. Biol. Proced. Online 3:19-25.

20. Mueller, E. E., and Grau, C. R. 2007. Seasonal progression, symptom development, and yield effects of Alfalfa mosaic virus epidemics on soybean in Wisconsin. Plant Dis. 91:266-272.

21. Mukasa, S. B., Rubaihayo, P. R., and Valkonen, J. P. T. 2006. Interactions between a crinivirus, an ipomovirus and a potyvirus in coinfected sweetpotato plants. Plant Pathol. 55:458-467.

22. Poolpol, P., and Inouye, T. 1986. Enhancement of cucumber mosaic virus multiplication by zucchini yellow mosaic virus in doubly infected cucumber plants. Ann. Phytopathol. Soc. Jpn. 52:22-30.

23. Pruss, G., Ge, X., Shi, X. M., Carrington, J. C., and Vance, V. B. 1997. Plant viral synergism: The potyviral genome encodes a broad-range pathogenicity enhancer that transactivates replication of heterologous viruses. Plant Cell 9:859-868
24. Ross, J. P. 1968. Effect of single and double infections of soybean mosaic virus and bean pod mottle viruses on soybean yield and seed characters. Plant Dis. Rep. 52:344-348.

25. Shi, X. M., Miller, H., Verchot, J., Carrington, J. C., and Vance, V. B. 1997. Mutations in the region encoding the central domain of helper component-proteinase (HC-Pro) eliminate potato virus $\mathrm{X} /$ potyviral synergism. Virology 231:35-42.

26. Tu, J. C. 1989. Effect of different strains of soybean mosaic virus on growth, maturity, yield, seed mottling and seed transmission in several soybean cultivars. J. Phytopathol. 126:231-236.

27. Vance, V. B. 1991. Replication of potato virus $\mathrm{X}$ RNA is altered in coinfections with potato virus Y. Virology 182:486-494.

28. Voinnet, O., Pinto, Y. M., and Baulcombe, D. C. 1999. Suppression of gene silencing: A general strategy used by diverse DNA and RNA viruses of plants. Proc. Natl. Acad. Sci. USA 96:14147-14152.

29. Wang, L., Eggenberger, A., Hill, J., and Bogdanove, A. J. 2006. Pseudomonas syringae effector $A v r B$ confers soybean cultivar-specific avirulence on Soybean mosaic virus adapted for transgene expression but effector AvrPto does not. Mol. Plant-Microbe Interact. 19:304-312.

30. Wang, R. Y., and Ghabrial, S. A. 2002. Effect of aphid behavior on efficiency of transmission of Soybean mosaic virus by the soybeancolonizing aphid, Aphis glycines. Plant Dis. 86:1260-1264.

31. Wintermantel, W. M., Cortez, A. A., Anchieta, A. G., Gulati-Sakhuja, A., and Hladky, L. L. 2008. Co-infection by two criniviruses alters accumulation of each virus in a host-specific manner and influences efficiency of virus transmission. Phytopathology 98:1340-1345.

32. Zhang, C. Q., and Ghabrial, S. A. 2006. Development of Bean pod mottle virus-based vectors for stable protein expression and sequence-specific virus-induced gene silencing in soybean. Virology 344:401-411. 